\title{
Gestão Pedagógica de Recursos Multifuncionais: um relato de experiência em uma escola de ensino fundamental no município de Mamanguape/PB, Brasil
}

\author{
Management of Multifunctional Educational \\ Resources: an experience at a primary school in the \\ city of Mamanguape/PB, Brazil
}

\author{
MARIANO CASTRO NETO \\ Universidade Federal da Paraíba
}

\begin{abstract}
Resumo: Este artigo $^{1}$ objetiva relatar a experiência realizada em uma escola pública no Município de Mamanguape/PB acerca da gestão pedagógica de recursos multifuncionais. Tratase de um estudo exploratório e descritivo. Como síntese final, pode-se afirmar que há evidências em relação ao aumento da demanda por salas de recursos multifuncionais nas escolas de Mamanguape/PB, portanto, ampliar e aprimorar os processos de gestão pedagógica de recursos multifuncionais tornam-se imperiosos nessa realidade. Como continuação desta pesquisa, procurou-se avaliar e identificar práticas pedagógicas bem sucedidas para pessoas com deficiência a partir do uso de recursos multifuncionais, além de buscar ampliar as discussões acerca da importância da gestão pedagógica desses recursos em escolas públicas.
\end{abstract}

Palavras-chave: Recursos multifuncionais. Pessoas com deficiência. Processo ensinoaprendizagem.

Abstract: This article aims to describe the experience in a public school in the municipality of Mamanguape, State of Paraiba, about the pedagogical management of multifunction capabilities. It is an exploratory and descriptive study. As summary, it can be said that there is evidence in relation to the increased demand for multi-functional resources in schools of Mamanguape, therefore growing and enhancing the educational process management of multifunctional features make up this imperious reality. The continuation of this research sought to evaluate and identify successful educational practices for people with disabilities from the use of multifunction capabilities, and seek to broaden discussions about the importance of pedagogical management of these public schools resources.

Keywords: Multifunction capabilities. Disabled people. Teaching-learningprocess.

CASTRO NETO, Mariano. Gestão Pedagógica de Recursos Multifuncionais: um relato de experiência em uma escola de ensino fundamental no município de Mamanguape/PB, Brasil. Informática na Educação: teoria \& prática, Porto Alegre, v. 19, n. 2, p. 41-49, jun./set. 2016.

${ }^{1}$ Este mesmo texto foi apresentado de forma incipiente no formato de um trabalho de conclusão de curso (EIRAS, 2014). 


\section{I ntrodução}

No Brasil, as políticas públicas voltadas à Educação Especial, tratadas inicialmente na Constituição Federal no ano de 1988, estabeleceram: “[...] promover o bem de todos, sem preconceitos de origem, raça, sexo, cor, idade e quaisquer outras formas de discriminação [...]" (BRASIL, 1988), em texto descrito no artigo 3o do inciso IV.

As implicações dessas concepções, no âmbito educacional brasileiro, influenciaram a elaboração de diretrizes para a construção de políticas públicas, com ênfase na Educação Especial, para pessoas com deficiência. Por sua relevância, a Lei de Diretrizes e Bases da Educação Nacional (LDBN) no 9.394/96 (BRASIL, 1996) dedica um capítulo exclusivo para esse tema.

Nessa perspectiva, institucionalizar discussões acerca da importância da gestão pedagógica de recursos multifuncionais envolve mudanças de práticas pedagógicas e implica envolvimento da comunidade escolar, discussões, reflexões e sistematizações acerca de ações pedagógicas integradas com as demais áreas do conhecimento humano, tendo como referência o projeto político pedagógico da escola e os objetivos de aprendizagem pretendidos (CASTRO NETO; FADEL; ULBRICHT, 2013).

A partir dessas questões, com base na revisão bibliográfica, se destacam autores como Castro Neto, Fadel e Ulbricht (2013), Eiras (2014), Luck (2009), Gil (2002), Vogel (2001), UNESCO (1994), dentre outros e problematizou-se acerca da importância da gestão pedagógica de recursos multifuncionais em uma escola do município de Mamanguape. Nesse sentido, sistematizou-se este estudo a partir do seguinte questionamento: Em que medida a gestão pedagógica de recursos multifuncionais, em uma escola de Mamanguape/PB, pode colaborar para um processo ensino-aprendizagem inclusivo para pessoas com deficiência?

Inicialmente, realizou-se o levantamento: do número de escolas com salas de recursos multifuncionais em Mamanguape, do número de pessoas com deficiência e tipos regularmente matriculados, e das dificuldades em relação aos conteúdos curriculares. Após a execução dessas etapas, identificou-se a escola onde se realizaria a empiria. Investigaram-se pesquisas bibliográficas em bancos de dados especializados e específicos da área. Buscou-se ainda a colaboração de experts (gestores, professores e responsáveis pela elaboração e implantação das salas de recursos multifuncionais no município de Mamanguape).

\section{Deficiência uma Questão Conceitual}

No Brasil, a Lei Federal no 7.853, de 24 de outubro de 1989 (BRASIL, 1989), regulamentada pelo Decreto no 3.298, de 20 de dezembro de 1999, é uma das mais importantes das legislações, quando se trata dos direitos de pessoas com deficiência. A referida lei classifica as deficiências, conforme mostra o Quadro 1. 
Quadro 1 - Classificação das Deficiências.

\begin{tabular}{|l|l|}
\hline Deficiência & $\begin{array}{l}\text { Alteração completa ou parcial de um ou mais segmentos do corpo humano, } \\
\text { aćsica } \\
\text { parraplandogia, paraparesia, monoplegia, monoparesia, tetraplegia, tetraparesia, } \\
\text { triplegia, triparesia, hemiplegia, hemiparesia, amputação ou ausência de membro, } \\
\text { paralisia cerebral, membros com deformidade congênita ou adquirida, exceto as } \\
\text { deformidades estéticas e as que não produzam dificuldades para o desempenho de } \\
\text { funções. }\end{array}$ \\
\hline $\begin{array}{l}\text { Deficiência } \\
\text { Mental }\end{array}$ & $\begin{array}{l}\text { Funcionamento intelectual significativamente inferior à média, com manifestação } \\
\text { adtes dos } 18 \text { anos e limitaçães associadas a duas ou mais áreas de habilidades } \\
\text { utilização da saúde e segurança, convivência, habilidades acadêmicas, lazer, } \\
\text { trabalho. }\end{array}$ \\
\hline $\begin{array}{l}\text { Deficiência } \\
\text { Visual }\end{array}$ & $\begin{array}{l}\text { Caracterizada por uma limitação no campo visual, pode variar de cegueira total à } \\
\text { visão subnormal. Neste caso, ocorre diminuição na percepção de cores e mais } \\
\text { dificuldades de adaptação à luz. }\end{array}$ \\
\hline $\begin{array}{l}\text { Deficiência } \\
\text { Auditiva }\end{array}$ & $\begin{array}{l}\text { Perda total ou parcial da capacidade de compreender a fala através do ouvido. Pode } \\
\text { ser surdez leve, nesse caso, a pessoa consegue se expressar oralmente e perceber } \\
\text { a voz humana com ou sem a utilização de um aparelho. Pode ser também surdez } \\
\text { profunda. }\end{array}$ \\
\hline
\end{tabular}

Fonte: Brasil (1989)

Segundo Vogel (2001), a conceituação de deficiência coube, no mundo moderno, à Medicina, não apenas por ser ela a primeira instância de intervenção nesses casos, mas também por causa da hegemonia do discurso médico no universo dos saberes cientificamente legitimados. Na convenção de Salamanca, ficou estabelecida como eixo principal a unificação da educação para todos, analisando políticas necessárias para qualificar o sistema educacional, escolas, no sentido de receberem toda e qualquer pessoa com deficiência (UNESCO, 1994).

O Brasil ratificou em 2008, a Convenção sobre os Direitos das Pessoas com Deficiência (BRASIL, 2008), adotada pela Organização das Nações Unidas (ONU), buscando defender e garantir condições de vida com dignidade a todas as pessoas que apresentam alguma deficiência. Outro grande avanço foi a alteração do modelo médico para o modelo social, o qual passa a esclarecer que o fator limitador é o meio em que a pessoa está inserida e não a deficiência em si, remetendo-nos à Classificação Internacional de Funcionalidades (CIF) (BRASIL, 2011).

Tal abordagem deixa claro que as deficiências não indicam, necessariamente, a presença de uma doença ou que o indivíduo deva ser considerado doente. Assim, a falta de acesso a bens e serviços deve ser solucionada de forma coletiva e com políticas públicas estruturantes para a equiparação de oportunidades. Para isso, a escola deve cumprir sua função social (BRASIL, 2011).

\section{Percurso Metodológico Deste Estudo}

Trata-se de um estudo exploratório e descritivo, pois, como afirma Gil (2002, p.41), “[...]proporciona maior familiaridade com o problema, com vistas a torná-lo mais explícito quando a produção científica sobre o problema a ser estudado é incipiente[ ...]". E neste caso, por abordar dados e problemas que demandam pesquisas, mas, cujo registro, em alguns casos, não se encontra documentado. 
Em se tratando de procedimentos metodológicos adotados, realizaram-se entrevistas com experts e com todos os envolvidos no processo de implantação da sala de recursos multifuncionais: gestores, estudantes, professores, pais e coordenadores do projeto da Secretaria de Educação Municipal de Mamanguape/PB.

No decorrer da pesquisa, foram realizadas visitas e observação participante à Sala de Recursos Multifuncionais em uma escola pública de Mamanguape/PB, objetivando conhecer as estratégias pedagógicas e metodologias bem sucedidas utilizadas pelos professores in loco aos estudantes com deficiência.

Para efeitos deste estudo, foi adotado como referência o Quadro 2 elaborado pela Secretaria de Educação Especial do Ministério da Educação (SEESP/MEC) que caracteriza, em relação aos equipamentos, uma Sala de Recursos Multifuncionais.

Quadro 2 - Equipamentos que Caracterizam uma Sala de Recursos Multifuncionais.

\begin{tabular}{|c|c|c|c|}
\hline Equipamentos & Mobiliários & \multicolumn{2}{|c|}{ Materiais Didático/ Pedagógico } \\
\hline 02 Microcomputadores & $\begin{array}{ll}01 & \text { Mesa } \\
\text { redonda } & \end{array}$ & 01 Material dourado & 01 Alfabeto Braille \\
\hline 01 Laptop & 04 Cadeiras & 01 Esquema corporal & 01 Kit de lupas manuais \\
\hline 01 Estabilizador & $\begin{array}{l}01 \text { Mesa para } \\
\text { I mpressora }\end{array}$ & 01 Bandinha rítmica & $\begin{array}{l}01 \text { Plano inclinado - suporte } \\
\text { para leitura }\end{array}$ \\
\hline 01 Scanner & 01 Armário & 01 Memória de numerais & 01 Dominó tátil \\
\hline 01 Impressora laser & $\begin{array}{ll}01 & \text { Quadro } \\
\text { branco } & \end{array}$ & $\begin{array}{l}01 \text { Tapete Alfabético } \\
\text { Encaixado }\end{array}$ & $\begin{array}{l}01 \text { Dominó de associação de } \\
\text { ideias }\end{array}$ \\
\hline 01 Teclado com colmeia & $\begin{array}{l}01 \text { Mesa para } \\
\text { computador }\end{array}$ & $\begin{array}{l}01 \text { Software comunicação } \\
\text { alternativa }\end{array}$ & 01 Dominó de frases \\
\hline 01 Acionador de Pressão & 02 Cadeiras & $\begin{array}{l}01 \text { Sacolão criativo monta } \\
\text { tudo }\end{array}$ & $\begin{array}{l}01 \text { Dominó de animais em } \\
\text { Libras }\end{array}$ \\
\hline $\begin{array}{l}01 \text { Mouse com entrada } \\
\text { para acionador }\end{array}$ & & $\begin{array}{l}01 \text { Quebra - cabeça } \\
\text { Sequência lógica }\end{array}$ & $\begin{array}{l}01 \text { Dominó de frutas em } \\
\text { Libras }\end{array}$ \\
\hline 01 Lupa eletrônica & & 01 Memória tátil & \\
\hline
\end{tabular}

Fonte: Brasil (2010)

O Programa Implantação de Salas de Recursos Multifuncionais é disponibilizado pelo MEC para todas as escolas públicas do Brasil. Porém, cabe aos gestores dos sistemas de ensino, definir critérios para sua implantação. Os recursos disponibilizados (kit sala de recursos multifuncionais) para a composição da sala são os constantes no Quadro 2.

A indicação das escolas a serem contempladas e o planejamento da oferta do Atendimento Educacional Especializado (AEE), conforme as demandas das escolas, devem atender aos critérios definidos pela SEESP/MEC, por meio dos seguintes critérios; a) a escola elabora o Plano de Ações Articuladas (PAR), registrando as demandas com base no diagnóstico da realidade educacional; b) a escola indicada deve ser da rede pública de ensino regular, conforme registro no Censo Escolar do Instituto Nacional de Estudos e Pesquisas Educacionais Anísio Teixeira (INEP) (escola comum); c) a escola de ensino regular deve ter matrícula de 
aluno(s), público alvo da Educação Especial em classe comum, registrado(s) no Censo Escolar/INEP, para a implantação da sala Tipo I; d) a escola de ensino regular deve ter matrícula de aluno(s) cego(s) em classe comum, registrado(s) no Censo Escolar/INEP, para a implantação da sala de Tipo II; e) a escola deve ter disponibilidade de espaço físico para o funcionamento da sala e professor para atuação no AEE(BRASIL, 2010).

Após a apresentação do projeto, da solicitação da sala de recursos multifuncionais e da confirmação da indicação da escola, bem como da disponibilização das salas pelo Programa, as Secretarias de educação devem: a) informar às escolas sobre sua indicação; b) monitorar a entrega e instalação dos recursos nas escolas; c) acompanhar o funcionamento da sala conforme os objetivos; d) promover a assistência técnica, a manutenção e a segurança dos recursos; e) apoiar a participação dos professores nos cursos de formação para o AEE; f) assinar e retornar ao SEESP/MEC o Contrato de Doação dos recursos.

\section{Processo de Implantação da Sala de Recursos Multifuncionais}

Segundo Luck (2009), podemos compreender gestão escolar a partir de áreas, dimensões e estratégias de intervenção organizadora, de caráter abrangente e catalisador de esforços em prol de mudanças e desenvolvimento dos processos educacionais, de modo que se tornem cada vez mais eficazes os processos ensino-aprendizagem. As estratégias organizadoras se referem à preparação, à ordenação, à provisão de recursos, à sistematização e à retroalimentação do trabalho a ser realizado para garantir uma estrutura administrativa básica necessária ao alcance dos objetivos de aprendizagem.

O Programa Implantação de Salas de Recursos Multifuncionais tem por objetivo apoiar a organização e a oferta do AEE, prestado de forma complementar ou suplementar, aos estudantes com deficiência, transtornos globais do desenvolvimento, altas habilidades/superdotação matriculados em classes comuns do ensino regular, assegurando-lhes condições de acesso, participação e aprendizagem (BRASIL, 2010). De acordo com a LDBN a escola, hoje, de ensino regular deve ofertar apoio necessário às pessoas com deficiência e assegurar o acesso à informação e ao desenvolvimento de competências e habilidades em uma perspectiva inclusiva.

Em meados de 1998, o município de Mamanguape foi contemplado com o Programa Implantação de Salas de Recursos Multifuncionais, que disponibilizou à escola um conjunto de equipamentos de informática, mobiliários, materiais pedagógicos e de acessibilidade para a organização do espaço de AEE. Entretanto, cabe ao sistema de ensino a seguinte contrapartida: disponibilização de espaço físico para implantação dos equipamentos, mobiliários e materiais didáticos e pedagógicos de acessibilidade, bem como a disponibilização do professor para atuar no AEE, além de garantir a formação continuada para os professores que atuam na Sala de Recursos Multifuncionais.

A partir desse novo momento, a Sala de Recursos Multifuncionais passou a funcionar em uma sala própria disponibilizada dentro da escola e contando com recursos didáticos e equipamentos tecnológicos desenvolvidos exclusivamente para a inclusão dos estudantes com deficiência, conforme mostrou o Quadro 2. 
Inicialmente, o espaço físico destinado à sala de recursos multifuncionais localizava-se em um prédio anexo, com quatro salas distintas. Para organizar o uso das salas, definiram-se quatro categorias. Pessoas com deficiências visual, auditiva, mental (severa) e motora. Inicialmente foram atendidas 24 (vinte e quatro) pessoas com deficiência.

Com uma demanda crescente e com a carência de dados acerca do quantitativo de pessoas com deficiência na região de Mamanguape, realizou-se um censo nas escolas a fim de conhecer o número de pessoas com deficiência no município de Mamanguape. Outras informações também foram levantadas, por exemplo, acerca do cotidiano de quem convive com pessoas com deficiência. De posse dessas informações, a Secretaria de Educação do município de Mamanguape articulou com o MEC, recursos e condições para a implantação das Salas de Recursos Multifuncionais, tendo como órgão responsável a Secretaria de Educação Continuada, Alfabetização, Diversidade e Inclusão (SECADI).

Os programas de formação continuada, ofertados pela Fundação de Apoio ao Deficiente (FUNAD) aos professores para a utilização pedagógica de recursos multifuncionais foram fundamentais para o avanço. Esses programas, mesmo que de forma tímida, possibilitaram aos professores qualificação para atender pessoas com deficiência.

\section{Gestão Pedagógica de Recursos Multifuncionais}

Inicialmente a utilização de recursos multifuncionais se realiza, juntamente com a professora regular, uma primeira sondagem nas salas regulares e identifica os tipos de deficiências e as possíveis dificuldades em se tratando da aprendizagem dos conteúdos. Com base nesses procedimentos, realiza-se a formação dos grupos. Após essa organização, iniciase, na sala de recursos multifuncionais, o atendimento individualizado ao estudante com deficiência, a partir de um planejamento que possibilite acompanhamento da seguinte forma: $2 \mathrm{~h}$ (duas) por turma e $1 \mathrm{~h}$ (uma) por estudante com deficiência que requer atenção individualizada.

O trabalho realizado na sala de recursos multifuncionais fica restrito apenas ao uso dos materiais pedagógicos disponíveis, como: catálogos; materiais de texturas; materiais de comprimento; alfabetos móveis; cartazes em Braille; materiais confeccionados manualmente pela professora.

Em alguns momentos das entrevistas realizadas com os colaboradores, percebeu-se que alguns dos recursos multifuncionais não apresentavam aparência de serem utilizados com frequência, alguns já obsoletos. Isso evidencia, de certa forma, a necessidade de formação continuada bem como de outros aspectos relacionados à instrumentalização da linguagem, em suas variadas dimensões, apresentadas no quarto parágrafo da conclusão deste artigo.

Em razão da limitação de espaço físico da sala que contém apenas 1 (uma) mesa com 5 (cinco) cadeiras e a quantidade atual de estudantes na escola, que pode chegar a 22 (vinte e dois) estudantes, o atendimento na sala de recursos multifuncionais pode sofrer alterações. Nesse caso, o tempo por turma e estudantes é o seguinte: 1h (uma) por turma; 1h (uma) hora por estudante que requer atenção individualizada de 1 h30 (uma) e meia a 2h (duas) por estudante. 
O planejamento de como utilizar os recursos multifuncionais é realizado em conjunto com professoras da sala regular e com a professora da sala de recursos multifuncionais. Essa integração objetiva facilitar o trabalho referente aos conteúdos abordados na sala regular para que os conteúdos sejam transpostos didaticamente aos estudantes com deficiência. As metodologias aplicadas nas aulas da sala de recursos multifuncionais são realizadas, seguindo o roteiro da sala regular, porém com estratégias diferenciadas. A aplicação dessas estratégias diferenciadas, segundo a coordenadora, depende do tipo de deficiência.

De outro lado, os familiares dos estudantes com deficiência, ao procurarem a FUNAD, a fim de conseguir apoio para a educação, em muitos casos, são orientados a matriculá-los nas escolas regulares. E, ao fazer isso, eles se tornam partícipes do processo ensino-aprendizagem dos filhos. Convidados pela escola, os pais participam de viagens, das atividades adicionais, das formações, das palestras e dos encontros, dando total apoio aos filhos. A escola periodicamente convida Psicólogos, Psicopedagogos, Fisioterapeutas e demais profissionais para acompanhar os pais e estudantes.

A gestão pedagógica de recursos multifuncionais requer definição de ações objetivas, metodologias de organização do trabalho, atividade de aprendizagem e critérios para avaliar a aprendizagem do estudante com deficiência. Requer planejamento didático-pedagógico do processo ensino-aprendizagem que defina o lugar e o papel do estudante com deficiência, do professor, dos meios e recursos multifuncionais a serem utilizados, a delimitação dos conteúdos de ensino, a problematização, a forma de apresentar no contexto do plano integral ensinoaprendizagem, e fundamentalmente os critérios de avaliação.

\section{Conclusões}

O desenvolvimento deste estudo permitiu tecer algumas considerações relevantes para problematizar a gestão pedagógica de recursos multifuncionais em uma escola pública do município de Mamanguape/PB.

Este estudo mostrou a abrangência do Programa Implantação de Salas de Recursos Multifuncionais para a escola no que se refere ao apoio às pessoas com deficiência que, por meio da utilização dos recursos multifuncionais; materiais didáticos e técnicas diferenciadas promovem, mesmo que de forma tímida, uma aprendizagem inclusiva de estudantes com deficiência na escola municipal de Mamanguape/PB.

Além disso, este estudo evidenciou que o desenvolvimento de novas concepções de aprendizagem, no contexto da utilização de recursos multifuncionais, para estudantes com deficiência, torna-se imperativo. Essas novas concepções de aprendizagem e de práticas pedagógicas pressupõem a formação de um sujeito protagonista, consciente de motivos e fins. Ou seja, sob a ótica pedagógica, trata-se de redefinir o lugar e o papel da atividade desenvolvida pelo estudante com deficiência, transformando-a em uma das principais fontes de apropriação do conhecimento.

Para além da utilização pedagógica de recursos multifuncionais, os colaboradores deste estudo apontaram a necessidade de implementar estratégias para formação continuada de professores em aspectos relacionados à utilização instrumental da linguagem, à compreensão e 
elaboração de textos, às peculiaridades da coerência lógica do discurso, à necessária diferenciação entre significado socialmente construído e sentido pessoalmente atribuído e às peculiaridades das funções semântica, sintática e pragmática das diferentes formas de linguagem.

Para os colaboradores deste estudo, processos ensino-aprendizagem, realizados em contextos de utilização de recursos multifuncionais para estudantes com deficiência, pressupõem uma discussão integral do processo nos seus aspectos de concepção curricular, procedimentos didático-pedagógicos, planejamento e organização das atividades de aprendizagem e métodos e meios de avaliação da aprendizagem, superando a tendência atual de reduzir a complexidade desse processo a um simples incremento de novos meios de ensino.

Há, portanto, um longo caminho a ser percorrido para o processo de gestão pedagógica de salas de recursos multifuncionais, no caso dessa investigação, em escolas de Mamanguape no que se refere às condições de infraestrutura física, tecnológicas e pedagógicas.

Como síntese final, pode-se afirmar que há evidências em relação ao aumento da demanda por salas de recursos multifuncionais nas escolas de Mamanguape/PB, portanto, ampliar e aprimorar os processos de gestão pedagógica de recursos multifuncionais tornam-se imprescindíveis. Como continuação desta pesquisa, procurar-se-á avaliar e identificar práticas pedagógicas bem sucedidas para pessoas com deficiência, a partir do uso de recursos multifuncionais, além de buscar ampliar as discussões acerca da importância da gestão pedagógica desses recursos em escolas públicas.

\section{Referências}

BRASIL. Constituição (1988). Constituição da República Federativa do Brasil. 35. ed. Brasília: Câmara dos Deputados/Centro de Documentação e Informação, 2012. (Edições Câmara).

BRASIL. Convenção Sobre os Direitos das Pessoas com Deficiência: Protocolo Facultativo à Convenção Sobre os Direitos das Pessoas com Deficiência: decreto legislativo no 186, de 09 de julho de 2008: decreto no 6.949, de 25 de agosto de 2009. 4. ed., rev. e atual. Brasília: Secretaria de Direitos Humanos, Secretaria Nacional de Promoção dos Direitos da Pessoa com Deficiência, 2011.

BRASIL. Lei no 7.853, de 24 de outubro de 1989. Dispõe sobre o apoio às pessoas portadoras de deficiência, sua integração social, sobre a Coordenadoria Nacional para Integração da Pessoa Portadora de Deficiência - Corde, institui a tutela jurisdicional de interesses coletivos ou difusos dessas pessoas, disciplina a atuação do Ministério Público, define crimes, e dá outras providências. Diário [da] República Federativa do Brasil, Brasília, 25 out. 1989.

BRASIL. Lei no 9.394, de 20 de dezembro de 1996. Estabelece as diretrizes e bases da educação nacional. Diário [da] República Federativa do Brasil, Brasília, 23 dez. 1996. Seção 1, p. 27833.

BRASIL. Ministério da Educação. Secretaria de Educação Especial. Manual de Orientação: Programa de Implantação de Salas de Recursos Multifuncionais. Brasília, 2010.

CASTRO NETO, M.; FADEL, L. M.; ULBRICHT, V. R. (Org.). Hipermídia e Acessibilidade na Era da Inclusão. J oão Pessoa: I deia, 2013.

EIRAS, J. de S. Processo de Implantação da Sala de Tecnologias Assistivas em uma Escola do Município de Mamanguape/PB. 2014. Trabalho de Conclusão de Curso (Licenciatura em Ciência da Computação)Universidade Federal da Paraíba, Paraíba, 2014.

GIL, A. C. Métodos e Técnicas de Pesquisa Social. 5. ed. São Paulo: Atlas, 1999.

LÜCK, H. Dimensões de Gestão Escolar e suas Competências. Curitiba: Positivo, 2009. 
Porto Alegre, v.19, n.2, jun./set. 2016

ISSN impresso 1516-084X ISSN digital 1982-1654

UNESCO. Declaração de Salamanca Sobre Princípios, Política e Práticas na Área das Necessidades Educativas Especiais. Salamanca, 1994.

VOGEL, Vera L. Pessoas Portadoras de Necessidades Especiais no Planfor, In VOGEL, Arno (org.). Trabalhando com a Diversidade no Planfor: raça/cor, gênero e pessoas portadoras de necessidades especiais. São Paulo: UNESP; Brasília: FLACSO do Brasil, 2001. P. 107-149.

Recebido em 16 de julho de 2015

Aprovado para publicação em 07 de março de 2016

Mariano Castro Neto

Universidade Federal da Paraíba, Brasil, castroneto.mariano@gmail.com 